\title{
Transcriptome-based analysis of lectins and carotenoid metabolism enzymes in amphipods of the Lake Baikal region
}

\author{
Polina Drozdova \\ Institute of Biology \\ Irkutsk State University; \\ Baikal Research Centre \\ Irkutsk, Russia \\ 0000-0003-3955-6105 \\ Yulia Lubyaga \\ Institute of Biology \\ Irkutsk State University; \\ Baikal Research Centre \\ Irkutsk, Russia \\ 0000-0002-2494-8723
}

\author{
Alexandra Dolgikh \\ Dept. of Genetics and Biotechnology \\ St. Petersburg State University; \\ Bioinformatics Institute \\ St. Petersburg, Russia \\ 0000-0003-1845-9701
}

\author{
Maxim Timofeyev \\ Institute of Biology \\ Irkutsk State University; \\ Baikal Research Centre \\ Irkutsk, Russia \\ 0000-0002-5250-6818
}

\author{
Anna Nazarova \\ Institute of Biology \\ Irkutsk State University \\ Irkutsk, Russia \\ 0000-0002-5388-2559
}

\begin{abstract}
In this work, we explored two groups of proteins, the carbohydrate-binding lectins and enzymes of carotenoid metabolism, in amphipods of the Lake Baikal region based on the available transcriptome data. We found that different species possess quite similar repertoires of these proteins. The obtained sequence data are instrumental for further molecularlevel exploration of amphipod physiology.
\end{abstract}

Keywords - Carotenoid metabolism, immunity, lectins, Crustacea, Amphipoda, Baikal

\section{Introduction}

The ancient Lake Baikal, located in Eastern Siberia, hosts a spectacular diversity of largely endemic fauna [1]. Among the most diverse groups of its inhabitants are amphipods (Crustacea, Malacostraca, Amphipoda), comprising over 350 species and subspecies in the lake. At the same time, shallow gulfs of the lake and smaller water bodies in the region are inhabited by just one species, which is a potential invader but so far not found in the open part of Lake Baikal [2]. A number of amphipod species of the Baikal region have been used in ecophysiology- and ecotoxicology-, and biomonitoringrelated studies [3-6, etc.]. An important contributor to the changes in the physiological state of an organism is its immune system. Recently, next-generation sequencing data for Baikal amphipods became available [7, 8], and these data can help in the exploration of the immune system of these emerging model species. In this work, we focused on two factors important for the immune system of crustaceans, lectins [9] and carotenoid metabolism [10].

\section{Materials and methods}

To check the presence of transcripts encoding putative lectins and carotenoid metabolism enzymes, we searched the available transcriptome assemblies of amphipods of the Baikal region [7, 8] with known sequences of these enzymes found in other species $[9,11$, etc. $]$ using the blastx and blastp algorithms of the ncbi-blast [12] and diamond [13] packages. Protein sequences were predicted with TransDecoder [14]. Estimation of the expression level was performed with Salmon [15] using a wrapper script provided by Trinity [14].

\section{Results and Discussion}

\section{Lectins}

Lectins are a very ancient and versatile group of proteins containing carbohydrate-binding domains. Members of different lectin subfamilies bind to various carbohydrates (e.g., mannosides, galactosides, sialic acids), even though the ranges of substrates are overlapping, have characteristic folds and act both inside the cells and in the extracellular matrix [16]. The results of the search for lectins were similar for two endemic amphipod species of Lake Baikal (Eulimnogammarus cyaneus and E. verrucosus) and a potential invader species, Gammarus lacustris (Table 1). Further exploration of the expression levels of these transcripts revealed a relatively high organism-level expression ( $>10$ transcripts per million) only in type $\mathrm{C}$ lectins in all three species.

This result may mean that some of the type $\mathrm{C}$ lectins are expressed constitutively and/or in multiple tissue types, while the other types are expressed only in particular types of cells or only in response to infection.

TABLE I. PRESENCE OF DIFFERENT FAMILIES OF LECTINS AND ENZYMES OF CAROTENOID METABOLISM IN AMPHIPOD TRANSCRIPTOMES

\begin{tabular}{|c|c|c|}
\hline Functional group & Protein (sub)family & $\begin{array}{l}\text { Number of } \\
\text { identified } \\
\text { transcripts }^{\mathrm{a}}\end{array}$ \\
\hline \multirow{5}{*}{ Lectins } & $\mathrm{C}$ & $136 / 111 / 159$ \\
\hline & $\mathrm{S}$ (galectin) & $14 / 9 / 13$ \\
\hline & $\mathrm{M}$ & $22 / 12 / 14$ \\
\hline & $\mathrm{L}$ & $10 / 8 / 9$ \\
\hline & $\mathrm{P}$ & $8 / 2 / 5$ \\
\hline \multirow{3}{*}{$\begin{array}{l}\text { Carotenoid } \\
\text { metabolism } \\
\text { enzymes }\end{array}$} & CrtW (ketolase) & $5 / 6 / 4$ \\
\hline & CrtZ (hydroxylase) & $48 / 35 / 21$ \\
\hline & CrtS & $117 / 84 / 138$ \\
\hline
\end{tabular}

\section{Carotenoid metabolism enzymes}

It is well-known that the absolute majority of animals do not synthesize carotenoids but need to rely on their presence in the food source, and crustaceans are no exception [17]. However, they are capable of bioconversion between carotenoids, mainly by oxidizing orange beta carotene present in their diets into dark-red astaxanthin via a cascade of four reactions. These reactions require two enzyme activities, a 3,3'-hydroxylase (CrtZ) and a ketolase (CrtW). These enzymes have been explored in marine bacteria [18]; moreover, some fungi seem to possess a bifunctional enzyme (CrtS) [19]. Thus, we looked for the known enzymes of these 
three groups from bacteria, fungi, and crustaceans and found that putative $\mathrm{CrtZ}$ and $\mathrm{CrtS}$ proteins were found in all transcriptomes, while CrtW proteins are much less widespread and diverse. It is important to note that the analysis included transcriptome assemblies derived from whole animals, i.e., including all symbiotic microorganisms, which can serve as the source of the identified enzymes (examples in Table 1).

Interestingly, no obvious difference between brightly colored deep red species and white-colored ones was found with this analysis. There are obviously other factors that contribute to the color formation, such as the level and composition of carotenoids, which can vary extensively between Baikal amphipod species [20], and carotenoid-biding proteins, which can form complexes of various colors [17].

\section{Conclusion}

The analysis of amphipod transcriptomes helped us discover many putative lectin and carotenoid metabolism enzyme sequences, which can be used in further molecularlevel exploration in studies of amphipods of the Baikal region.

\section{ACKNOWLEDGMENT}

The study of carotenoid metabolism enzymes was supported by the Russian Science Foundation, project number 19-74-0045. The study of lectins was funded by the RFBR and the Government of the Irkutsk Region, project number 19-42383007.

\section{REFERENCES}

[1] M. E. Cristescu, S. J. Adamowicz, J. J. Vaillant, and D. G. Haffner, "Ancient lakes revisited: from the ecology to the genetics of speciation," Molecular Ecology, vol. 19, no. 22, 2010, pp. 4837-4851.

[2] V. V. Takhteev, "On the current state of taxonomy of the Baikal Lake amphipods (Crustacea: Amphipoda) and the typological ways of constructing their system," Arthropoda Selecta, vol. 28, no. 3, 2018 , pp. 374-402.

[3] M. A. Timofeyev, C. Wiegand, B. K. Burnison, Z. M. Shatilina, S Pflugmacher, C. E. W. Steinberg, "Impact of natural organic matter (NOM) on freshwater amphipods," Science of the Total Environment, vol. 319, no. 1-3, 2004, pp. 115-121.

[4] D. Axenov-Gribanov, D. Bedulina, Z. Shatilina, L. Jakob, K Vereshchagina, Y. Lubyaga et al., "Thermal preference ranges correlate with stable signals of universal stress markers in Lake Baikal endemic and Holarctic amphipods," PloS ONE, vol. 11, no. 10, 2016, 0164226 .

[5] L. Jakob, D. S. Bedulina, D. V. Axenov-Gribanov, M. Ginzburg, Z. M. Shatilina, Y. A. Lubyaga et al., "Uptake kinetics and subcellular compartmentalization explain lethal but not sublethal effects of cadmium in two closely related amphipod species," Environmental science \& technology, vol. 51, no. 12, 2017, pp. 7208-7218.
[6] A. Gurkov, E. Shchapova, D. Bedulina, B. Baduev, E. Borvinskaya, I. Meglinski, M. Timofeyev, "Remote in vivo stress assessment of aquatic animals with microencapsulated biomarkers for environmental monitoring," Scientific reports, vol. 6, no. 1, 2016, 36427.

[7] S. A. Naumenko, M. D. Logacheva, N. V. Popova, A. V. Klepikova, A. A. Penin, G. A. Bazykin et al., "Transcriptome-based phylogeny of endemic Lake Baikal amphipod species flock: fast speciation accompanied by frequent episodes of positive selection," Molecular ecology, vol. 26, no. 2, 2017, pp. 536-553.

[8] P. Drozdova, L. Rivarola-Duarte, D. Bedulina, D. Axenov-Gribanov, S. Schreiber, A. Gurkov et al., "Comparison between transcriptomic responses to short-term stress exposures of a common Holarctic and endemic Lake Baikal amphipods," BMC genomics, vol. 20, no. 1, 2019, 712.

[9] A. G. Lai, A. A. Aboobaker, "Comparative genomic analysis of innate immunity reveals novel and conserved components in crustacean food crop species," BMC genomics, vol. 18, no. 1, 2017, 389.

[10] K. Tan, H. Zhang, L.-S. Lim, H. Ma, S. Li, H. Zheng, "Roles of carotenoids in invertebrate immunology," Frontiers in Immunology, vol. 10, 2020, 3041 .

[11] N. Mojib, M. Amad, M. Thimma, N. Aldanondo, M. Kumaran, X. Irigoien, "Carotenoid metabolic profiling and transcriptome-genome mining reveal functional equivalence among blue-pigmented copepods and appendicularia," Molecular ecology, vol. 23, no. 11, 2014, pp. 2740-2756.

[12] C. Camacho, G. Coulouris, V. Avagyan, N. Ma, J. Papadopoulos, K. Bealer, T. L. Madden. "BLAST+: architecture and applications," BMC bioinformatics, vol. 10, no. 1, 2009, 421

[13] B. Buchfink, C. Xie, and D. H. Huson, "Fast and sensitive protein alignment using DIAMOND," Nature methods, vol. 12, no. 1, 2015, pp. 59-60.

[14] B. J. Haas, A. Papanicolaou, M. Yassour, M. Grabherr, P. D. Blood, J. Bowden, et al., "De novo transcript sequence reconstruction from RNA-seq using the Trinity platform for reference generation and analysis," Nature protocols, vol. 8, no. 8, 2013, pp. 1494-1512.

[15] R. Patro, G. Duggal, M. I. Love, R. A. Irizarry, and C. Kingsford, "Salmon provides fast and bias-aware quantification of transcript expression," Nature methods, vol. 14, no. 4, 2017, pp. 417-419.

[16] G. S. Gupta, "Lectins: An Overview", in Animal lectins: form, function and clinical applications, Springer Science \& Business Media: Vienna, 2012, pp. 3-25.

[17] T. Maoka. "Carotenoids as natural functional pigments," Journal of natural medicines, vol. 74, 2019, pp. 1-16.

[18] D. P. L. Toews, N. R. Hofmeister, and S. A. Taylor, "The evolution and genetics of carotenoid processing in animals," Trends in Genetics, vol. 33, no. 3, 2017, pp. 171-182.

[19] J. F. Martín, E. Gudiña, and J. L. Barredo, "Conversion of $\beta$-carotene into astaxanthin: Two separate enzymes or a bifunctional hydroxylaseketolase protein?," Microbial Cell Factories, vol. 7, no. 1, 2008, p. 3.

[20] B. Czeczuga, "Carotenoids in thirteen species of gammaridae from Lake Bajkał," Comparative Biochemistry and Physiology Part B: Comparative Biochemistry, vol. 50, no. 2, 1975, pp. 259-268. 